\title{
Rectal Adenoma with Severe Dysplasia
}

National Cancer Institute

\section{Source}

National Cancer Institute. Rectal Adenoma with Severe Dysplasia. NCI Thesaurus. Code C5621.

An adenoma that arises from the rectum. It is characterized by the presence of severe epithelial dysplasia. 